\title{
A PRODUÇÃO DO ARTESANATO GUARANI NO MUNICÍPIO DE DOURADOS, MATO GROSSO DO SUL
}

\author{
LEILA ROQUE RIBEIRO MARQUES ${ }^{1}$ \\ Universidade Estadual de Mato Grosso do Sul \\ GILBERTO LUIZ ALVES ${ }^{2}$ \\ Universidade Anhanguera-Uniderp
}

\begin{abstract}
RESUMO: Este artigo tem por objeto o artesanato guarani produzido na Reserva Indígena de Dourados, estado de Mato Grosso do Sul. O referencial teórico envolve categorias de análise buscadas em estudos de especialistas da matéria e obras de referência. Por meio de observações sistemáticas, de registros fotográficos e de entrevistas semiestruturadas, em especial com os artesãos, além de fontes secundárias, foram levantadas informações que permitiram identificar os objetos produzidos, as matérias-primas utilizadas, as origens do material empregado e as mudanças que impactaram o processo de produção e os produtos artesanais.
\end{abstract}

PALAVRAS-CHAVE: desenvolvimento regional; artesanato indígena; Kaiowá; Nandeva.

ABSTRACT: This article aims to analyze the Guarani handicraft produced in the Dourados Indigenous Reserve, Mato Grosso do Sul, Brazil. The theoretical reference involves analysis categories sought in studies by experts in the field and reference works. Data was collected through systematic observations, photographic records and semi-structured interviews, in special with artisans, in addition to secondary sources, in order to identify the objects produced, the raw materials used, the origins of the material used and the changes that impacted the crafting process and the final product.

KEYWORDS: regional development; Indigenous handicraft; Kaiowá; Nandeva.

\footnotetext{
1 Técnica em Assuntos Educacionais da Universidade Estadual de Mato Grosso do Sul. Professora da rede básica de ensino do Estado de Mato Grosso do Sul. E-mail: leilaroque@gmail.com

${ }^{2}$ Professor-pesquisador da Universidade Anhanguera-Uniderp. Doutorado e estudos de pós-doutorado em Educação pela Universidade Estadual de Campinas. E-mail: gilbertoalves9@uol.com.br
} 


\section{Introdução}

Este trabalho tem por objeto a produção do artesanato guarani, realizada na Reserva Indígena de Dourados, estado de Mato Grosso do $\mathrm{Sul}^{3}$. Seu objetivo foi descrever e analisar os produtos das modalidades de artesanato cultivadas na atualidade e compará-los com seus similares do passado, visando detectar mudanças ocorridas. Foram descritos o processo de produção, os objetos produzidos, as funções a eles incorporadas e as matérias-primas utilizadas.

Os Guarani dividem-se em três grupos: os Ñandeva, os Kaiowá e os Mbyá (SHADEN, 1962). Em Dourados, Mato Grosso do Sul, predominam os Guarani-Kaiowá e Guarani-Ñandeva. "São os habitantes nativos mais numerosos de Mato Grosso do Sul" (PACHOALICK, 2008, p. 27).

São pertencentes ao tronco Tupi e à família linguística TupiGuarani (WENCESLAU, 1990). No passado eram agricultores, produziam diversos cultivares e praticavam a caça, a pesca e a coleta (QUADROS, 2012). Quanto à organização social, predominava a família extensa, grupo composto por várias famílias, que viviam congregadas (CHAMORRO, 2008).

A economia dos Guarani era coletiva e as tarefas eram divididas por sexo. As mulheres produziam cerâmica, faziam os trabalhos domésticos e cultivavam a roça. Os homens caçavam, pescavam, faziam coleta de produtos naturais, eram os principais responsáveis pelos rituais religiosos, guerreavam e defendiam o grupo (QUADROS, 2012).

De acordo com Brum "o artesanato guarani está profundamente imbricado com seu sistema religioso. Encontramos referências aos cestos e trançados em várias partes de seus mitos" (BRUM, 2004, p. 9). No passado, seus objetos artesanais supriam necessidades básicas da etnia, tanto os utensílios destinados ao conforto, quanto os objetos utilizados em rituais. A produção artesanal envolvia artefatos cerâmicos, trançados, roupas de algodão, armas, adornos e instrumentos musicais (PASCHOALICK, 2008).

Quanto à abordagem teórica, foi importante levar em conta a mudança experimentada pelos produtos artesanais que transitaram de utensílios para a condição de mercadorias. Esse trânsito expressa mudanças mais profundas ocorridas na cultura Guarani. Ao assumirem a condição predominante de valores de troca, as peças artesanais revelaram, de fato, a profunda transformação ocorrida no modo de vida dos Guarani, decorrente do contato com a sociedade capitalista (RIBEIRO, 1984).

Por isso, para entender a produção artesanal dos Guarani, foi necessário o conhecimento da trajetória histórica dessa etnia. Ao saber como viviam e como se relacionavam no interior de suas práticas culturais, foi possível compreender o artesanato como componente dos

\footnotetext{
${ }^{3} \mathrm{O}$ projeto de pesquisa correspondente foi aprovado pelo Comitê de Ética da Universidade AnhangueraUniderp (Processo CAAE 43460215.8.0000.5161. Parecer número 1.283.080, aprovado em 15/10/2015).
} 
ritos e mitos dessa etnia, de suas crenças, de seus hábitos e costumes, de seu modo de viver, etc. Em resumo, entender o modo de vida dos Guarani foi condição essencial para compreender a produção de seu artesanato (PASCHOALICK, 2008).

\section{Material e métodos}

O universo da pesquisa é representado pelos Kaiowá e Nãndeva, reunidos na Reserva Indígena de Dourados. Em 2013, conforme dados da Secretaria Especial de Saúde Indígena, a população dessa reserva se elevava a 12.837 habitantes, distribuída em duas aldeias: Jaguapiru e Bororó. Dominante, o contingente das etnias Guaran-Kaiowá e GuaraniNãndeva era constituído por 9.994 membros. Também vivia no local uma minoria Terena composta por 2.843 indivíduos.

O município de Dourados, situado na região sul do estado de Mato Grosso do Sul, tem como coordenadas geográficas a latitude $22^{\circ} 13^{\prime} 16^{\prime \prime} \mathrm{S}$ e a longitude $54^{\circ} 48^{\prime} 2$. Sua altitude é de $452 \mathrm{~m}$ e se estende por uma superfície correspondente a $4.086 .237 \mathrm{~km}^{2}$. Possui clima subtropical e seu solo é do tipo latossolo vermelho, distroférrico de textura argilosa (GOMES et al., 2007).

A reserva indígena está situada ao norte da cidade de Dourados, próxima do centro urbano, e possui uma área de 3.539 hectares. Sua vegetação era dominada por florestas compactas. De acordo com Santana Junior, "a região que corresponde à atual reserva, bem como às áreas vizinhas, eram, no início do século XX, tomadas por densas matas" (2010, p. 212).

Soares e Pereira também confirmam que, "originariamente, a vegetação da área era composta predominantemente pela Floresta Estacional Semidecidual estando a mesma restrita aos fragmentos florestais remanescentes distribuídos na reserva" (SOARES; PEREIRA, 2015, p. 7).

O deslocamento de colonos para a região, no interior do movimento conhecido como Marcha para o Oeste, e a expansão da agricultura, a partir do final da década de 1960, realizaram amplo e profundo desmatamento na região. Ao longo do tempo, a vegetação nativa foi substituída por monoculturas de soja, milho e cana de açúcar.

Atualmente, a vegetação da área compreendida na reserva indígena apresenta degradação, em decorrência de extração de madeira, principalmente de espécies vegetais do subdossel para obtenção de lenha e pelo impacto do cultivo agrícola, além do desmatamento que cada vez mais fragmenta os habitats remanescentes (GOMES et al., 2007).

Quanto à metodologia utilizada, a descrição e a análise da produção artesanal guarani, suas técnicas de produção, matérias-primas utilizadas e sua disponibilidade demandaram observações de campo, feitas na Reserva Indígena de Dourados ao longo do mês de outubro de 
2015. As observações sistemáticas incidiram sobre o cotidiano dos artesãos envolvidos em suas atividades costumeiras. Por meio das diversas visitas, foram realizadas, também, entrevistas semiestruturadas com artesãos, imagens fotográficas dos objetos produzidos e coleta de alguns deles.

As entrevistas com roteiros semiestruturados foram realizadas, na maioria dos casos, com marido e mulher e, em alguns, envolveram também filhos, em suas residências, confeccionando ou não artesanato. Foi entrevistado, também, o biólogo Cajetano Vera, gestor ambiental da Coordenaria de Assuntos Indígenas da Prefeitura Municipal de Dourados, órgão que se localiza dentro da reserva indígena. Suas informações ajudaram a esclarecer e a confirmar relatos dos artesãos. Posteriormente, os depoimentos dos entrevistados foram transcritos, analisados e interpretados.

Foram utilizados, também, registros fotográficos e coleta de artefatos artesanais atualmente produzidos pelos índios. São peças como colares, brincos, cocares, arcos e flechas, cestos trançados, tapetes e redes feitos no tear, além de instrumentos como o chocalho e o taquapú 4 , bastão oco de ritmo. As matérias-primas identificadas são sementes de plantas nativas, penas, linha, lã, barbante, fibra de caraguatá, bambu, madeira, embira ${ }^{5}$ de bananeira, cipó e cabaça.

Através das entrevistas semiestruturadas e da observação do processo de produção dos objetos, foram identificadas as matériasprimas utilizadas, sua disponibilidade na reserva indígena e as funções dos artefatos confeccionados atualmente. Com a descrição obtida, tornou-se possível comparar as características do artesanato guarani atual em relação ao artesanato ancestral, cujos traços identificadores foram buscados na literatura especializada, sobretudo nos estudos de Ribeiro (1988) e Paschoalick (2008).

Quando necessário, fontes secundárias sobre a matéria foram utilizadas para complementar a base de dados empíricos.

\section{Resultados e discussões}

Através das entrevistas com os artesãos, observou-se que o artesanato produzido atualmente na Reserva Indígena de Dourados é composto por objetos trançados, tecidos, armas, adornos e instrumentos musicais.

\subsection{Trançados}

Conforme Ribeiro (1988), os trançados se classificam, segundo suas finalidades, em objetos de uso e conforto doméstico, objetos de caça e pesca, objetos para processamento da mandioca, objetos de

\footnotetext{
4 "Tubo oco de madeira leve ou bambu percutido verticalmente contra o solo" (RIBEIRO, 1988, p. 197).

${ }^{5}$ Fibra de bananeira.
} 
transporte de carga e de adorno pessoal.

Esses artefatos possuíam várias funções associadas às necessidades diárias da existência dos Guarani. O abano servia para atiçar o fogo; o cesto tinha por finalidade o armazenamento de frutas e de sementes; a esteira prestava-se ao descanso e para dormir; os cestosarmadilhas eram essenciais à caça e à pesca; a peneira, tipiti, era usada para o processamento da mandioca, e o cesto cargueiro funcionava como meio de transporte. Os trançados também serviam de adorno em chapéus, braçadeiras e cintos (PASCHOALICK, 2008).

Tais produtos eram confeccionados com matérias-primas diversas, como a palha, a tala do buriti, as gramíneas, os marantáceos como arumã, as fasquias de cipó e as palmeiras como babaçu e bacaba (RIBEIRO, 1987).

De acordo com Métraux (2012), os Guarani eram especialistas na produção de cestos. Usavam como matérias-primas o cipó guaimbé (Philodendron selloum, Koch) e a taquara (PASCHOALICK, 2008).

Atualmente, os trançados produzidos pelos Guarani da Reserva Indígena de Dourados se resumem a poucos objetos: os abanos para atiçar o fogo, as peneiras e os cestos.

Figura 1 - Peneiras e cesto confeccionados pela Artesã Antônia Aparecida. Matériasprimas: fibra de palmeira e taquara

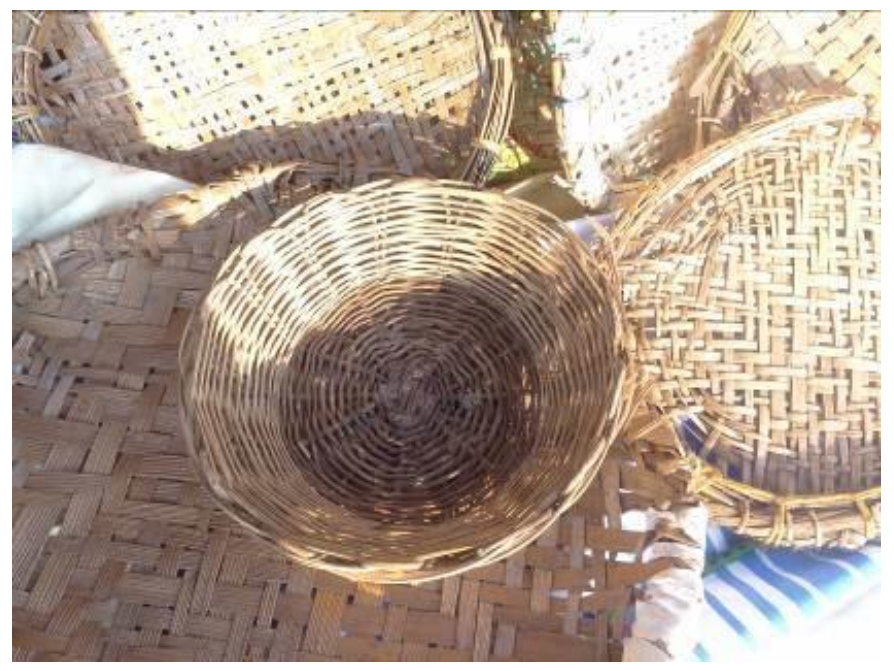

Fonte: MARQUES, 2016.

Em relação às matérias-primas utilizadas atualmente, constatou-se o emprego do bambu, da taquara, do cipó, da folha de palmeira, da fibra do caule de palmeira e da embira de bananeira. O cacique Jorge da Silva e a artesã Antônia Aparecida cultivam nos quintais de suas casas plantas utilizadas na produção de peças artesanais. Também procuram compensar as carências da reserva, decorrentes do desmatamento, com matérias-primas buscadas em outras aldeias da região.

\footnotetext{
${ }^{6}$ Trepadeira que se enrosca em árvores, utilizada para fazer trançados (PASCHOALICK, 2008).
} 
Figura 2 - Cesto produzido pelo artesão Alex Souza da Silva. Matérias-primas: embira de bananeira e tintas industriais

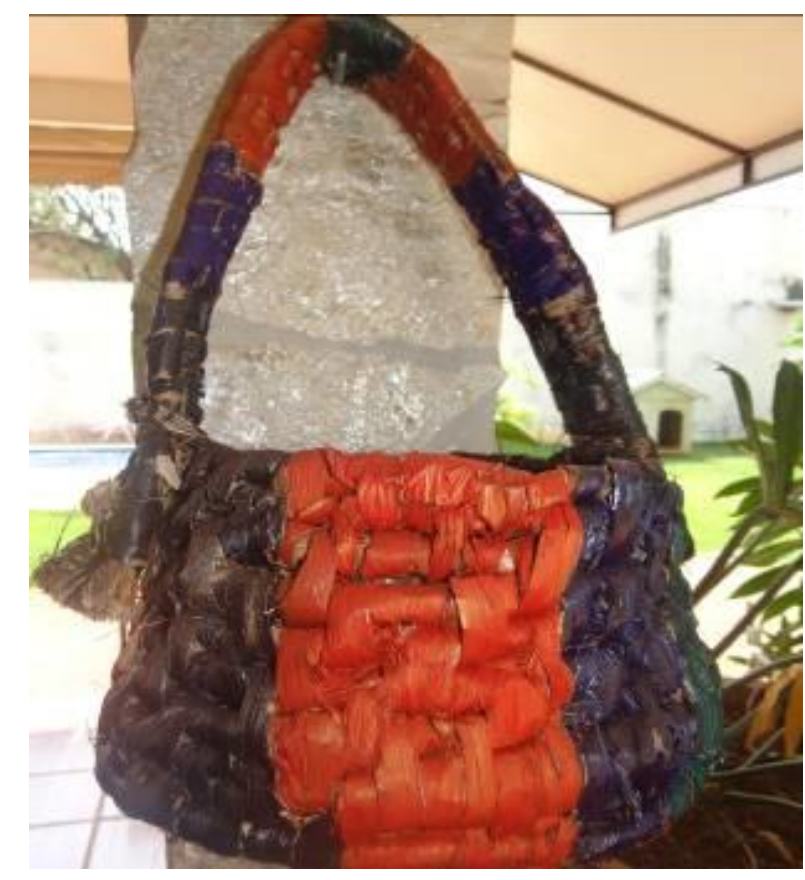

Fonte: MARQUES, 2016.

O cacique Jorge da Silva se referiu à extinção da taboca, essencial à produção de algumas peças trançadas, e associou-a ao desmatamento ocorrido na área da reserva:

Antigamente tinha aquela tal taboca. Taboca é um tipo de taquara que dava é, no mato, assim, que ninguém ridicava, né? Você chegava lá, cortava e levava pra fazer, e agora acabou aquele lá, desmatou tudo nosso mato, nossa vivência, né? $E$ a gente vai plantando e o pessoal vai plantando taquarinha (DA SILVA, 2015).

A artesã Antônia Aparecida explicou que cultiva a taquara no quintal de sua casa e a emprega na produção artesanal. Também recolhe os caules de palmeiras que encontra na cidade. Ela os retira dos jardins das residências e os utiliza na confecção de alguns de seus trançados.

O artesão Alex Souza da Silva, filho do cacique Jorge da Silva, faz uso da embira de bananeira, cultivada no quintal da residência dos pais, para a produção de cestos destinados ao comércio.

Também o artesão Roberto Arce utiliza bambu e cipó guaimbé na confecção de trançados. O cipó em referência só é utilizado quando trazido da aldeia Piraquá, situada no município de Bela Vista.

Percebem-se, nos relatos do cacique Jorge e de Antônia Aparecida, 
as dificuldades encontradas para produzir artesanato devido ao desmatamento ocorrido na reserva. "Você vê na Reserva indígena não tem, assim, árvore, não tem mato assim, é, não tem mais" (APARECIDA, 2015).

Alguns objetos trançados deixaram de ser produzidos devido às alterações sofridas na maneira de viver dos Guarani. Substituídos por outros objetos, deixaram de ter utilidade, o que contribui para seu desaparecimento.

A cestaria não é muito praticada no momento pelos Kaiowá e isto se deve, sobretudo, pelo fato de não ter mais utilidade no novo modo de ser, tekoyahu, visto que está diretamente relacionada ao transporte por terra de crianças e carga, para uso e conforto doméstico como suporte de cabaça, abanador, esteira, entre outros (PASCHOALICK, 2008, p. 66).

Ao longo da realização do trabalho de campo, objetos como cestos-armadilhas, cestos-cargueiros, gaiolas, tipiti, chapéus e tipoias não foram encontrados na Reserva Indígena de Dourados.

\subsection{Tecelagem}

Conforme definição de Ribeiro, tecelagem "é a técnica de interpor regularmente os fios, com ou sem o uso de implementos e aparelhos" (RIBEIRO, 1988, p. 92).

Os Guarani utilizavam o algodão para produção de tecidos. Com o uso do tear, teciam e confeccionavam vestuários masculinos e femininos. Fiar, tingir e tecer eram tarefas atribuídas às mulheres (SHADEN, 1962).

Métrax, ao descrever o processo de tecelagem entre as Guarani, observou também que as mulheres teciam "sem ajuda de nenhum instrumento, passando simplesmente os fios da trama entre aqueles da urdidura como se elas remendassem" (MÉTRAX, 2012, p. 322).

$\mathrm{Na}$ descrição das técnicas básicas de tecelagem, Ribeiro (1988) afirma que

a arte de tecer admite duas macro-divisões: trabalho em trama e trabalho em malha. A primeira pressupõe o uso de um dispositivo para a tensão dos fios da urdidura: o tear. E o uso de dois elementos, urdidura e trama ou dois conjuntos de elementos que se entrecruzam formando o tecido. A segunda se processa pelo emprego de um único elemento contínuo de tamanho finito ou infinito, e o uso ou não de um implemento, agulha de ponta (tricô), agulha de gancho (crochê) ou agulha de orifício (enlace), ou simplesmente um gabarito (RIBEIRO, 1988, p. 92). 
Conforme Schaden (1962), com o processo da tecelagem os Guarani produziam tecidos e confeccionavam roupas. O vestuário masculino era composto do ponchito, um poncho pequeno, o txumbé (faixa de algodão usada em torno da cintura) e o txiripá, pano de algodão de forma retangular, com três lados de franja que desce até abaixo dos joelhos. O vestuário feminino era composto do váta, que corresponde a uma blusa, e o tupái, semelhante a uma saia.

Com o uso das fibras de caraguatá (Bromelia antiancatha), planta da família das bromeliáceas, as índias guarani também produziam fios. Com eles, confeccionavam redes, utilizadas para as crianças dormirem dentro de casa e, também, para descansar (PASCHOALICK, 2008).

No que se refere às vestimentas confeccionadas com o uso do algodão, estas deixaram de ser produzidas. A indumentária masculina atualmente é confeccionada com tecidos industrializados. Trajes tradicionais, de acordo com Paschoalick (2008, p. 72), são utilizados "apenas em ocasiões especiais de apresentação das danças ou outros rituais".

Observa-se atualmente que as tecelãs, "pela ausência do algodão e do caraguatá abandonaram a prática de fiar, povã, [...] [mas] continuam tecendo com barbante, lã, fios de tecidos desfiados, estopa, linha, utilizando a mesma técnica dos seus antepassados" (PASCHOALICK, 2008, p. 68).

A artesã Antônia Aparecida faz uso de tear confeccionado por ela e pelo esposo, o artesão Admiro Arce. Com barbante, produzem redes. Também a artesã Marilda Duarte elabora faixas e tapetes com o recurso do tear. Para substituir o algodão, ela utiliza o barbante e a lã, comprados em casas comerciais da cidade.

Figura 3 - Tapetes e faixas produzidos com tear pela artesã Marilda Duarte. Matériasprimas: barbante e lã

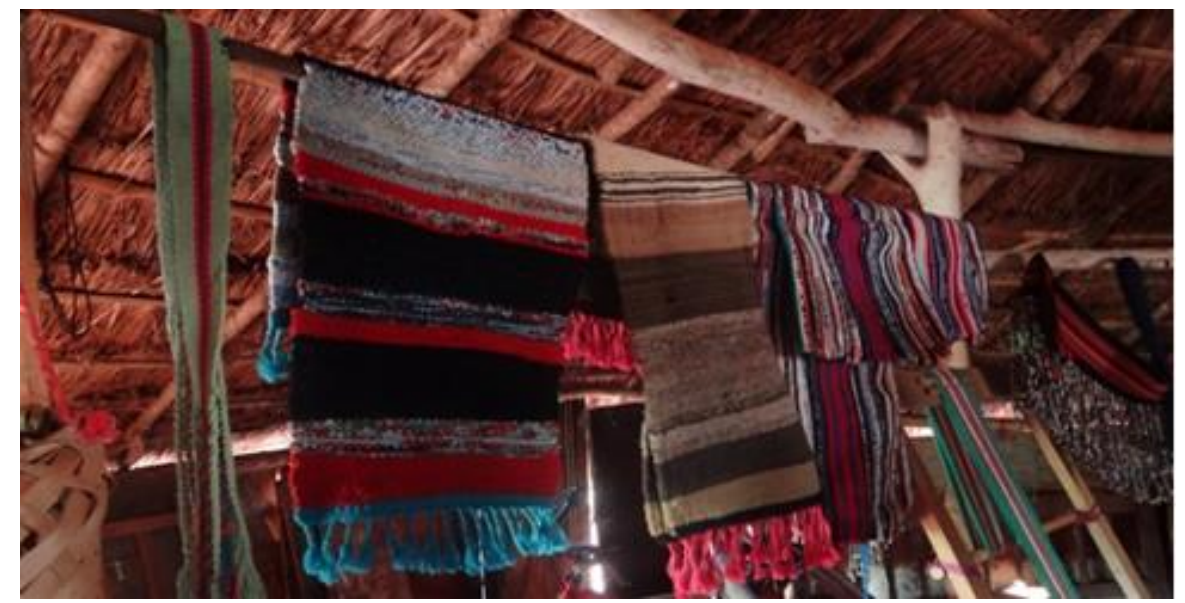

Fonte: MARQUES, 2016. 
As faixas, produzidas atualmente pela artesã Marilda Duarte, servem à confecção de saias. Envolvem uma variedade de sementes nativas e têm como destino o mercado.

Figura 4 - Saias confeccionadas pela artesã Marilda Duarte. Matérias-primas: barbante e sementes nativas

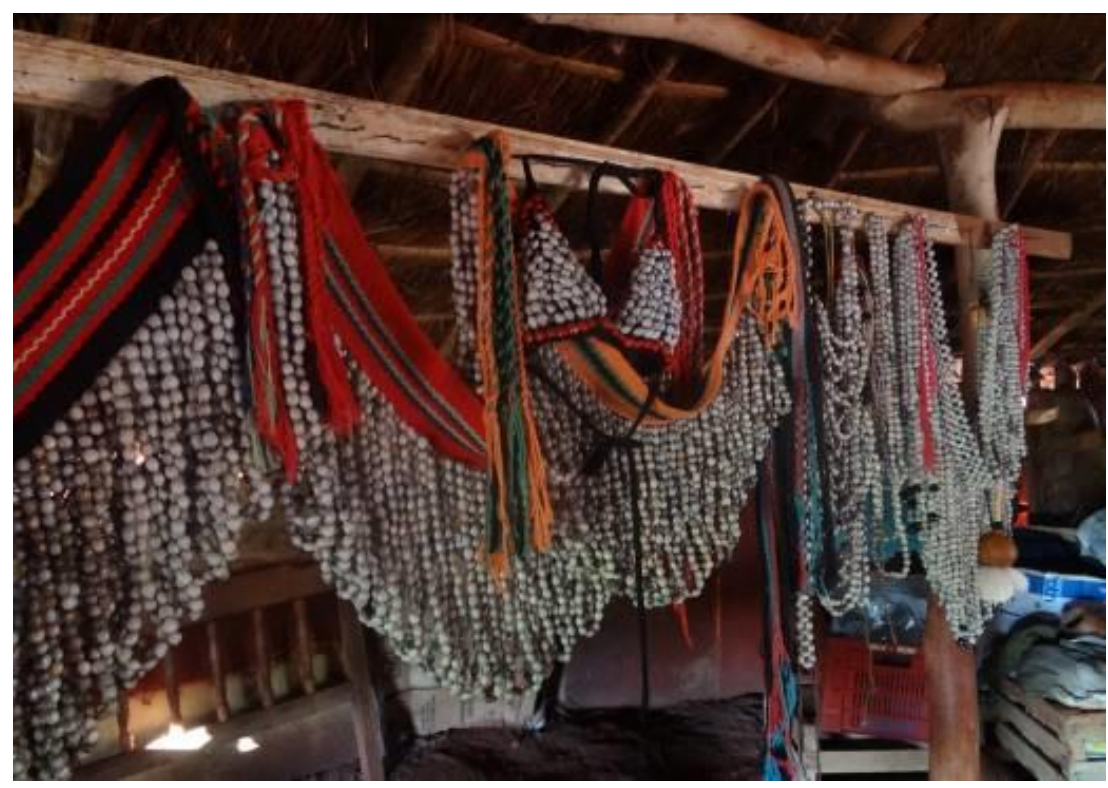

Fonte: MARQUES, 2016.

Juntamente com o tear artesanal, Marilda Duarte faz uso de tear industrial, adquirido por meio de doação. A artesã informou que utiliza tanto um quanto o outro na confecção das peças que produz.

\subsection{Armas}

Segundo Ribeiro, armas são "o conjunto de objetos empregados indiscriminadamente para as funções de guerra e para as tarefas de provimento da subsistência, tais como a caça e a pesca" (RIBEIRO, 1988, p. 239). A mesma autora ainda as classifica em três categorias: armas de arremesso, armas de choque e armas de sopro.

As armas de arremesso, como a lança, a boleadeira, o arco e a flecha, servem para ataque a pequena, média ou grande distâncias. As armas de choque, como a borduna, se aplicam ao combate próximo ou à caça a animais de grande porte. As armas de sopro são aquelas que contêm dardos envenenados (RIBEIRO, 1988).

Paschoalick (2008, p. 51) destaca que as "armas dos indígenas brasileiros que mais se destacam são as de 'ataque', utilizadas para a guerra, caça e pesca". Segundo Chiara (1987, p. 118), "as armas mais convencionais utilizadas pelos índios são: sarabatana, propulsor de dardos, boleadeiras, borduna (conhecida também como clava ou macana), lança e arco e flecha". 
As armas deixaram de ter utilidade no modo de viver atual dos Guarani em Dourados. A caça e a pesca já não são praticadas em decorrência do desmatamento e do confinamento em reserva a que foi submetida a etnia (PASCHOALICK, 2008).

Por não haver necessidade dos objetos que se aplicam a essas atividades, na atualidade, eles deixaram de ser produzidos como utensílios. Entretanto, a produção do arco e da flecha permanece, agora como mercadoria. Direcionadas ao mercado, são produzidas, desde a origem, com finalidade comercial.

Em relação às matérias-primas utilizadas na produção do arco e da flecha, Métraux (1987, p. 140) diz que ambos eram confeccionados com variados tipos de madeira, como a aroeira (Astronium spp.), o pau d'arco (Tecoma af. Conspícua DC), o ipê (Tabebuia sp.), a caraúba (Jacaranda copaia) e a pupunha (Bactris speciosa), entre outros.

De acordo com os artesãos guarani de Dourados, os arcos e flechas são canalizados para o mercado. Passaram a ser miniaturizados, pois, nessa condição, são acondicionados mais facilmente nas bagagens dos compradores, predominantemente, turistas.

Em relação às matérias-primas utilizadas, no presente, os artesãos informaram que se servem de madeiras como o aguaí (Thevetia peruviana), o cipó guaimbé (Philodendron bipinnatifidum) e a taquara. Para o trançado do arco são utilizados, além do cipó, o capim braquiária, a linha e o barbante. Já foi mencionado que o cipó guaimbé está extinto na reserva e só é utilizado quando trazido de outras aldeias da região.

O caraguatá, quando encontrado, é utilizado para fazer o cordão dos arcos. Na falta do caraguatá, é empregado o barbante. As penas que adornam as peças são de galinhas, tingidas com papel crepom, anilina e outras tintas compradas em casas comerciais da cidade.

Figura 5 - Arcos e flechas em miniatura confeccionados pelo artesão Jorge da Silva. Matérias-primas: bambu, taquara, barbante e penas coloridas

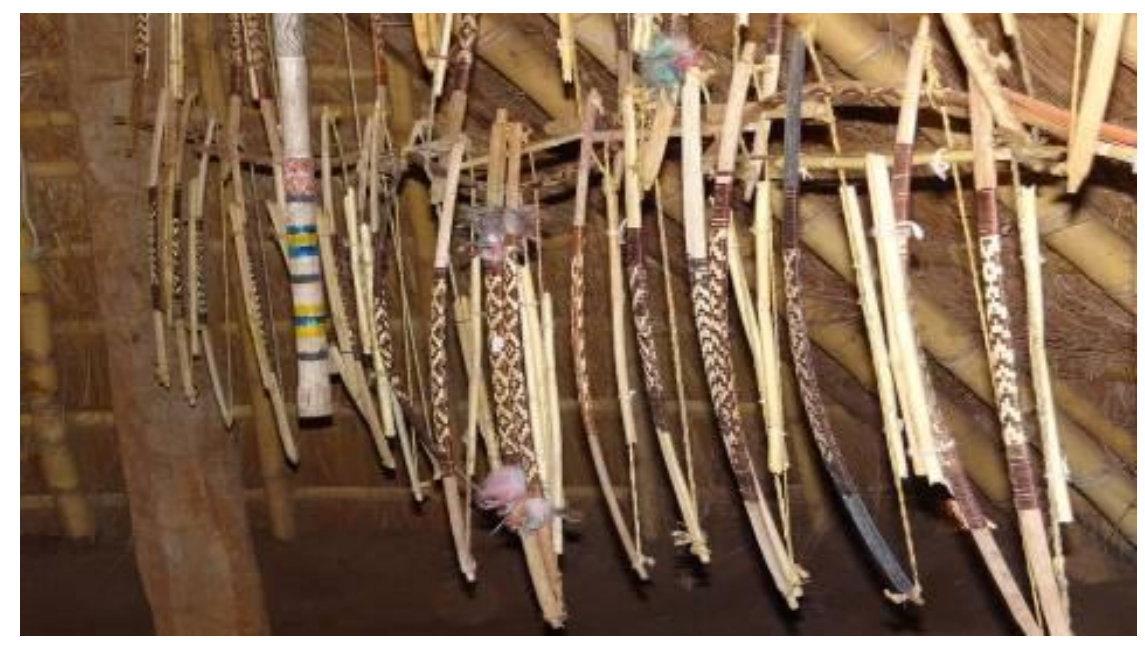

Fonte: MARQUES, 2016. 
Os arcos e flechas produzidos pela artesã Antônia Aparecida, juntamente com seu esposo, o artesão Adimiro Arce, têm como matérias-primas caule de palmeira, taquara, cordão de caraguatá, cipó e penas coloridas. De acordo com a artesã, o caraguatá é encontrado na própria reserva. O caule de palmeira é colhido na cidade, na condição de material de descarte de jardins. Com carroça, ela transporta o produto até a reserva. A família de artesãos confecciona arcos e flechas em miniatura e, também, em tamanhos maiores. Alguns atingem até $143 \mathrm{~cm}$ de comprimento, como foi aferido durante observação na reserva.

\subsection{Cerâmica}

Para Ribeiro, cerâmica é a "arte de confeccionar artefatos com argila submetidos à combustão e alta temperatura" (RIBEIRO, 1988, p. 30).

Em relação às funções dos artefatos cerâmicos na vida dos indígenas, Willey (1987) diz que eram produzidos pelas etnias indígenas como utensílios para armazenar, preparar e consumir alimentos sólidos e líquidos. Algumas peças também tinham função "religiosa", como aquelas empregadas como urnas mortuárias.

De acordo com Paschoalick (2008), a cerâmica foi prática cultural muito difundida entre os Guarani e tem sido recurso essencial para identificação étnica em sítios arqueológicos. Conforme Kashimoto e Martins (2008), a cerâmica guarani tem sido coletada em vários sítios arqueológicos no atual estado de Mato Grosso do Sul:

Datações arqueológicas obtidas a partir de amostras coletadas na margem sul-mato-grossense do rio Paraná, o baixo curso do Ivinhema, na atual reserva dos índios Kadiwéu, ou ainda na margem do córrego Lalima, pequeno afluente do rio Miranda, são evidências incontestes da produção de cerâmica arqueológica, Tupiguarani ou Guarani em Mato Grosso do Sul, nos séculos XVI, XVII e XVIII, as quais estratigraficamente, atestam as sequências ocupacionais a partir de horizontes deposicionais pré-coloniais (KASHIMOTO; MARTINS, 2008, p. 153).

No conjunto de objetos artesanais produzidos pelos Guarani, na Reserva Indígena de Dourados atualmente não foram encontradas peças cerâmicas.

Os artesãos relataram a ocorrência de dificuldades para produzir cerâmica. O artesão Jorge da Silva afirmou que ainda há aqueles que dominam as técnicas associadas à produção de peças cerâmicas. Reconheceu também que há argila na reserva. Mas ninguém produzia, segundo sua justificativa, pois inexistia madeira disponível apropriada para a queima das peças. O artesão também esclareceu que comprar 
madeira para esse fim seria inviável, pois elevaria muito o custo de produção.

O artesão Roberto justificou que não produzia cerâmica porque não dispunha de um local adequado para guardar as peças. Elas deterioram quando expostas em local aberto.

Em relação ao abandono dessa atividade, Paschoalick observa que "alguns aspectos podem ter contribuído para esse fato, como o conhecimento do metal, o deslocamento dos indígenas de suas aldeias tradicionais e o confinamento em reservas" (PASCHOALICK, 2008, p. 94).

De acordo com a autora citada, o novo modo de viver imposto aos Guarani pela sociedade capitalista contribuiu para 0 abandono da prática oleira.

\subsection{Adornos}

Conforme Ribeiro (1988), adornos são objetos usados para ornamentar o corpo. Sua produção envolve diversas matérias-primas, envolvendo recursos da flora, da fauna, minerais e, inclusive, produtos industriais.

Adornos também são definidos como objetos que expressam características étnicas dos grupos produtores.

São adereços de uso ritual ou cotidiano e indicadores da condição etária, sexual, social e étnica. São elaborados com materiais de origem vegetal, cabaça, castanhas, bambu, lágrima de Nossa Senhora; animal, pêlos, dentes, ossos, penas; mineral, granito, sílex, entre outros (PASCHOALICK, 2008, p. 55).

Conforme Paschoalick (2008), com esses materiais, são produzidos objetos como os colares, os cocares, os tembetás, as pulseiras, as braçadeiras, as tornozeleiras, as saias, os cintos e os brincos.

De acordo com os artesãos guarani da reserva de Dourados, entre os adornos mais produzidos atualmente estão os colares, as pulseiras, os palitos para cabelo e os brincos. Na confecção desses objetos são empregados a casca de coco, a taquara e variados tipos de sementes de plantas nativas. Podem ser referidas as sementes de pau-brasil (Caesalpinia echinata), de lágrima de nossa senhora (Coix lacryma-job), de pariri (Arrabidaea Chica), de olho de cabra (Ormosia arbórea), de leucena (Leucaena leucocephala), de saboneteira (Sapindus saponária) e de açaí (Euterpe oleracea Mart.).

Também são utilizadas penas de galinhas. Para dar-lhes cores variadas os artesãos utilizam tintas industriais como a anilina ou decorrentes do papel crepom. A artesã Floriza, esposa do cacique Jorge, lembra que, no passado, eram utilizadas tintas extraídas de plantas para colorir os adornos. Uma dessas plantas era o catiguá (Trichilia 
emarginata).

Figura 6 - Colares de sementes nativas produzidos pela artesã Marilda Duarte

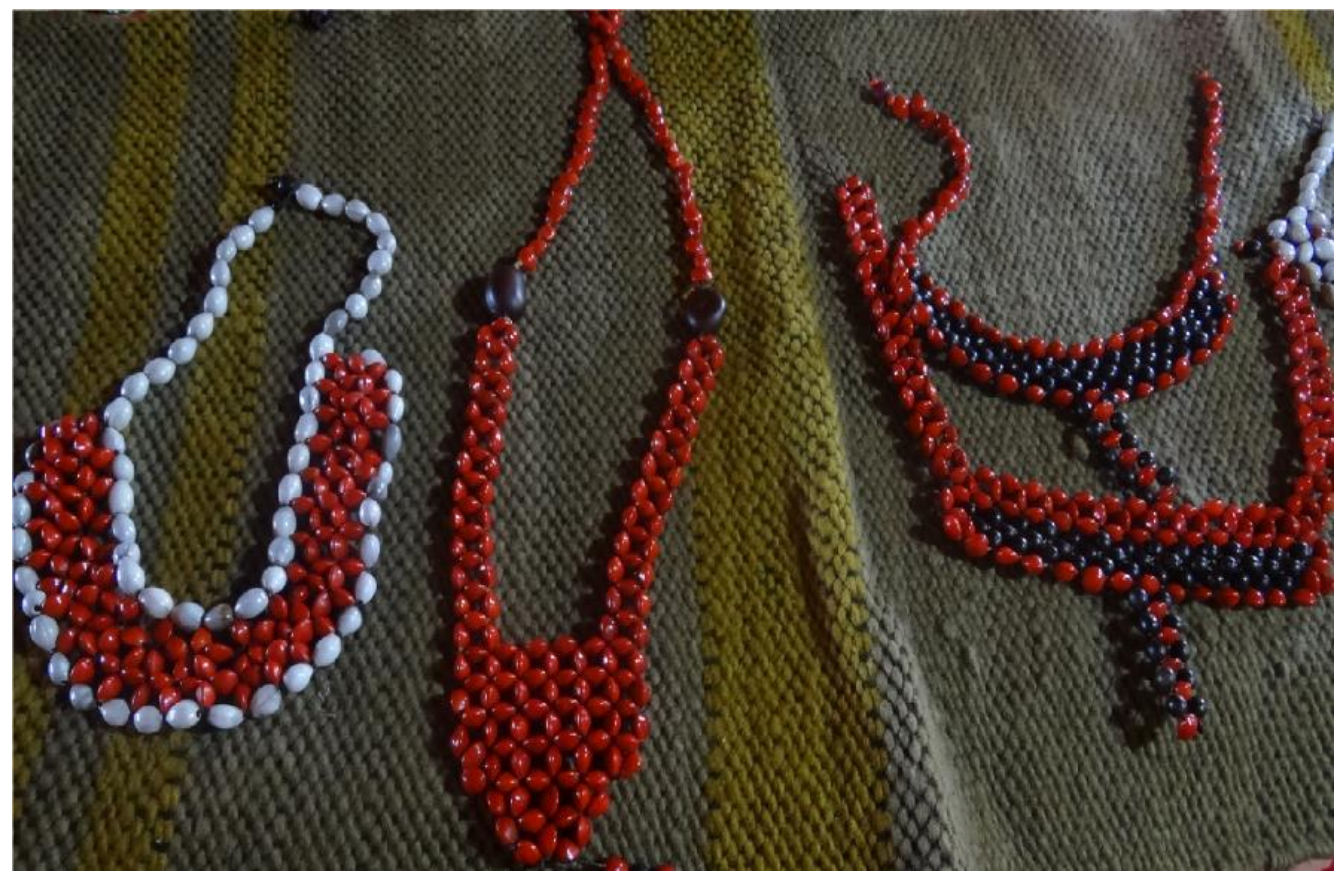

Fonte: MARQUES, 2016.

Conforme relato dos artesãos, no conjunto das matérias-primas empregadas atualmente, foram introduzidos materiais não utilizados pelos Guarani no passado. São as linhas, o barbante e a semente de açaí, levada do estado do Pará.

Ainda quanto à substituição de matérias-primas para a produção de colares, Paschoalick (2008, p. 60) afirma que "o cordão no qual passam sementes era, tradicionalmente, confeccionado de fio de caraguatá, agora substituído pelo fio de nylon ou linha".

Foi possível observar que algumas plantas utilizadas na confecção do artesanato são cultivadas pelos próprios artesãos nos quintais de suas casas. O cacique Jorge da Silva cultiva matérias-primas como a cabaça (Crescentia cujete), utilizada para fazer chocalhos, e o pariri (Arrabidaea chica), empregado na confecção de colares. Quanto às sementes, o artesão explica que todas devem ser colhidas na lua cheia para não carunchar.

Entre os objetos produzidos, se firmam aqueles que têm maior aceitação no mercado. Como o objetivo dos indígenas é a venda, a procura interfere na seleção das peças que devem ser produzidas em maior quantidade. A ausência de procura pode, inclusive, levar ao abandono da produção de certas peças. A artesã Claudia Nunes afirma que produz muitos brincos porque são adornos muito procurados. 
Figura 7 - Brincos e colares confeccionados pela artesã Claudia Nunes. Matériasprimas: penas coloridas, sementes nativas e barbante

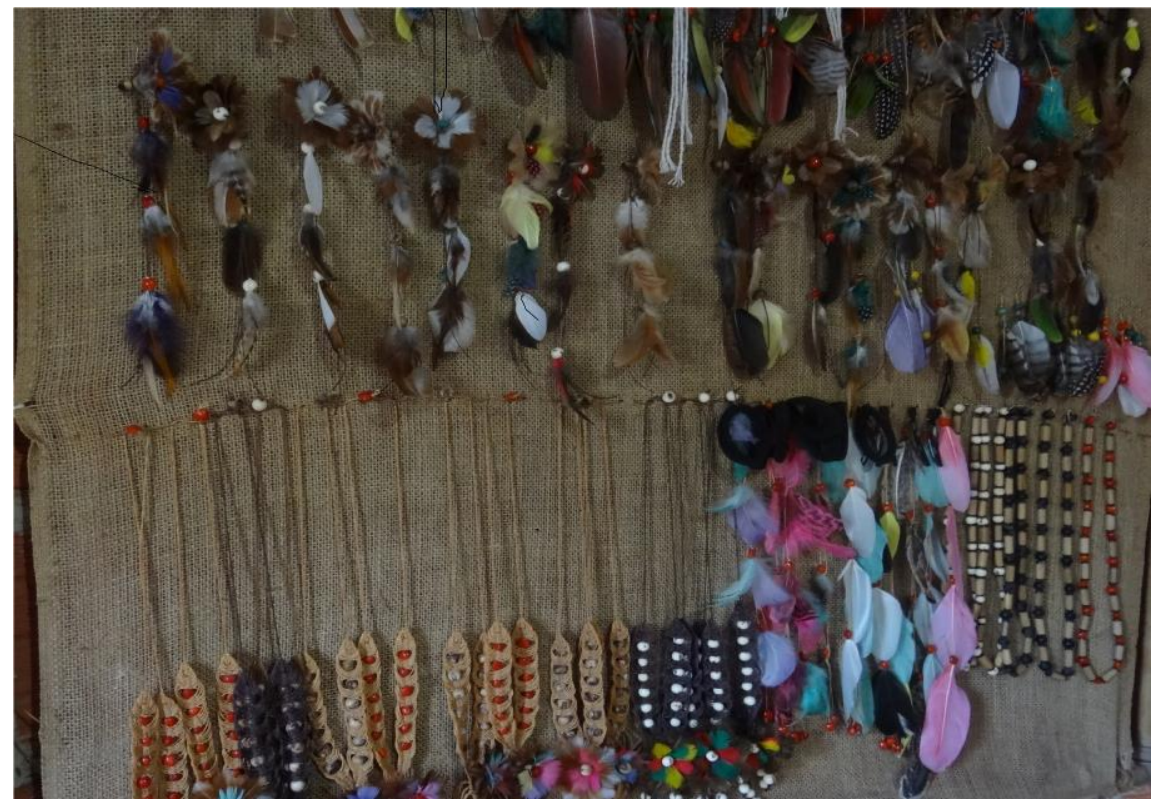

Fonte: MARQUES, 2016.

Figura 8 - Cocar confeccionado pela artesã Antônia Aparecida. Matérias-primas: penas coloridas, taquara e cipó

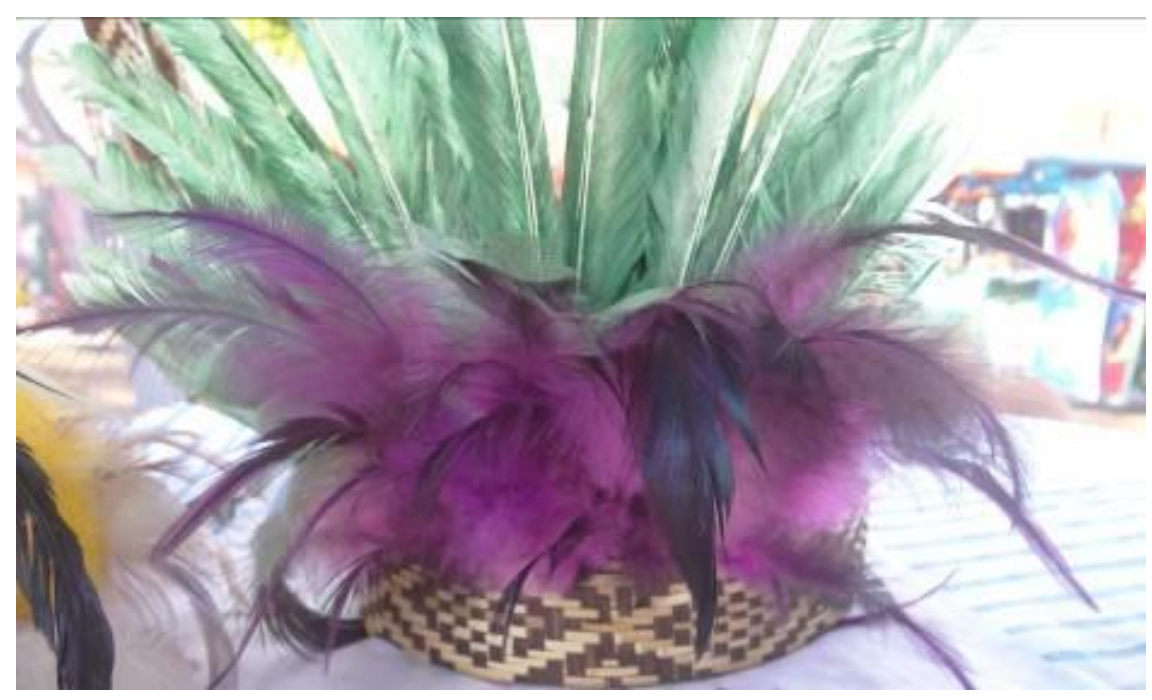

Fonte: MARQUES, 2016.

\subsection{Instrumentos musicais}

A música ocupou lugar de grande importância na vida das etnias indígenas. Entre elas, segundo Seeger (1987), a música sempre se associou à ocorrência de eventos relevantes.

Ao se referir à relação existente entre os povos indígenas e a 
música, Ribeiro (1987, p. 141) observou que "a música e os instrumentos musicais se relacionam a aspectos da organização social e da cosmologia. O rito é invariavelmente, um evento musical".

Os instrumentos musicais na América do Sul
compartilham da importância da música. São tidos,
frequentemente, pelos nativos como objetos que
incorporam um poder identificado com diversas
espécies de espíritos, seres ou grupos de pessoas
(SEEGER, 1987, p. 174).

Quanto aos instrumentos musicais, Ribeiro (1988) os classifica em quatro grupos: aerofones, cordofones, idiofones e membranofones.

Os aerofones são instrumentos que produzem som mediante a vibração do ar soprado no interior de um receptáculo. Incluem-se nessa classificação os instrumentos de sopro. Os cordofones são instrumentos que produzem som mediante a vibração de cordas. Os idiofones são instrumentos sonoros entre os quais se classificam o chocalho e o bastão oco de ritmo. Os membranofones são instrumentos dotados de caixa de ressonância.

As matérias-primas utilizadas para a produção dos instrumentos musicais são de origem vegetal, animal e mineral. Entre elas. podem ser citadas a madeira, a taquara, o bambu, a cabaça e as sementes nativas.

A dança e o canto são práticas culturais muito difundidas entre os Guarani-Kaiowá. Eles se dispõem a cantar e dançar quando recebem visitas. Os instrumentos musicais utilizados nesses momentos são o maracá, mbaracá, e o bastão oco de ritmo, taquapu, que produz som ao ser batido no chão e é feito de bambu (PASCHOALICK, 2008). Atualmente, é produzido pelos Guarani o maracá, um chocalho feito de cabaça. Para tanto, nesta se abre um orifício onde são introduzidos sementes e um cabo de madeira. Também é confeccionado com taquara um bastão oco de ritmo. Esses instrumentos são usados em danças e, também, em rituais.

A artesã Marilda produz alguns chocalhos para uso da família e outros direcionados à comercialização. Não são percebidas diferenças no processo de confecção de ambos, nem nos próprios produtos.

A ausência de certas matérias-primas para a confecção de algumas peças artesanais é entendida por Cajetano Vera, biólogo indígena e gestor ambiental da Coordenadoria Especial em Assuntos Indígenas da Prefeitura Municipal de Dourados, como uma das principais dificuldades para a manutenção e a expansão do artesanato indígena. Como forma de minorar essa limitação, verifica-se que alguns artesãos se preocupam com o cultivo de plantas associadas à produção no quintal de suas casas. É o que acontece com o cacique Jorge da Silva. No quintal de sua casa são encontrados o pariri, a cabaça e a bananeira.

Segundo o gestor ambiental, as queimadas, comuns em estação seca, são responsáveis pela destruição de muitas plantas que fornecem 
matérias-primas para o artesanato.

Figura 9 - Chocalhos confeccionados pela artesã Marilda Duarte. Matérias-primas: cabaça, linha e madeira

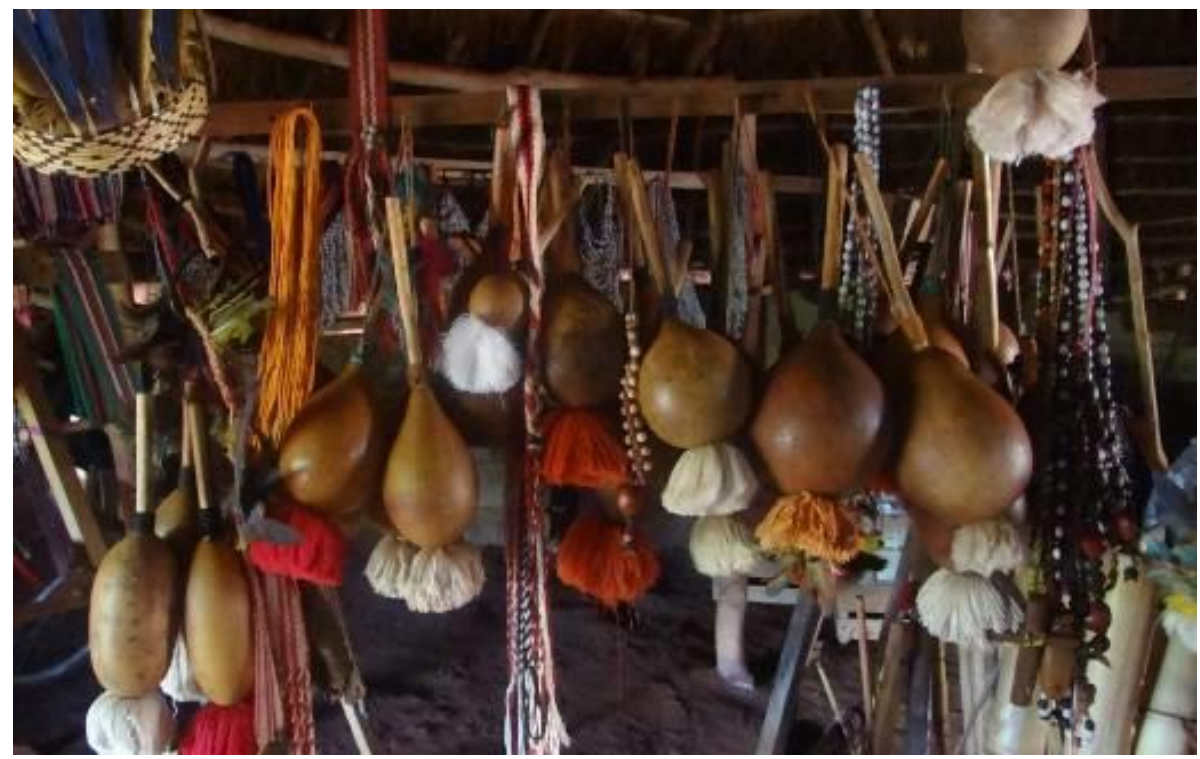

Fonte: MARQUES, 2016.

O gestor se referiu também à proposta corrente de reflorestamento da reserva indígena, que teria como um de seus objetivos prover os artesãos das plantas em referência. Sua viabilidade, porém, esbarrou na diminuta área disponível na reserva. A proposta mantém-se estagnada e não terá condições de avançar enquanto não for superada a limitação apontada.

\section{Conclusão}

Através da análise realizada, foi possível identificar mudanças ocorridas na produção artesanal que se realiza na Reserva Indígena de Dourados. Constatou-se o abandono da produção de peças cerâmicas, de tecidos, de alguns trançados, além de outros objetos que já não têm utilidade no presente.

Quando questionados sobre a finalidade da produção artesanal na atualidade, todos os artesãos afirmaram que produzem para 0 comércio. A exceção fica por conta de alguns objetos utilizados em rituais religiosos. Dessa forma, perdeu predominância a produção de utensílios - com valores de uso, em favor de mercadorias - com valores de troca.

Entre os fatores que contribuíram para as mudanças no artesanato dos Guarani em Dourados, o mais importante foi decorrência do longo período de contato com a sociedade capitalista, que ocasionou 
transformações no seu habitat e no próprio modo de viver dessa etnia. Esse fato se expressa nas funções distintas incorporadas às peças artesanais no passado e na atualidade.

Foi superada a produção de artefatos antes produzidos para suprir necessidades básicas dessa etnia, a exemplo da cerâmica, utilizada para cozinhar e armazenar água e alimentos; do arco e da flecha, empregados na caça e na pesca, e dos tecidos de algodão, usados no fabrico de roupas. Valores de uso, tão somente, deixaram de ter utilidade na nova maneira de viver dos Guarani. Em contato com a sociedade capitalista, esses produtos utilitários foram substituídos por outros, como as vasilhas de alumínio, armas de fogo e tecidos industrializados adquiridos no mercado. Algumas das antigas peças artesanais desapareceram. Outras, mesmo quando ainda produzidos, o são por valor de troca, direcionadas para o mercado.

Em Dourados, a falta de algumas matérias-primas em decorrência do desmatamento sofrido pela reserva indígena e pelo seu entorno vem dificultando a produção de artesanato indígena guarani. Algumas foram substituídas, como os corantes naturais, os cordões de caraguatá e as penas de aves nativas. Para a permanência do artesanato, foram incorporados ao repertório de matérias-primas atuais as tintas industriais, o barbante e penas de galinha tingidas. As dimensões das peças também foram impactadas pelas mudanças. Alguns objetos passaram a ser miniaturizados como forma de atender às conveniências dos turistas, que podem acomodá-los mais facilmente em suas bagagens.

Todas as mudanças, em resumo, evidenciam alterações ambientais. A decorrente escassez de certas matérias-primas impõe ajustes. Para manter-se e atender às demandas do mercado, o artesanato guarani vem improvisando substituições de matérias-primas ancestrais por produtos industrializadas ou importados de outras regiões.

\section{Referências bibliográficas}

APARECIDA, A. Depoimento recolhido durante entrevista na Reserva Indígena de Dourados, Dourados, 2015.

BRUM, B. D. Artesanato Guarani Mbyá do Rio de Janeiro: Apontamentos para uma Abordagem Discursiva. Textos Escolhidos de Cultura e Arte Popular, Rio de Janeiro, v. 1, n. 1, p. 7-16, 2004.

CHAMORRO, G. Terra madura - Yvy araguyje: fundamento da palavra Guarani. Dourados: Ed. da UFGD, 2008. 
CHIARA, V. Armas: bases para uma classificação. In: RIBEIRO, D. (ed.). Suma Etnológica Brasileira, v. 2. Petrópolis: 1987. p. 117-137.

GOMES, A. A et. al. Avaliação do impacto da fragmentação de florestas nativas sobre a mesofauna edáfica da região de Dourados-MS. Ciência e agrotecnologia, Lavras, v. 31, n. 3, p. 612-618, maio/jun., 2007.

KASHIMOTO, E. M; MARTINS, G. R. A problemática arqueológica da tradição cerâmica tupi-guarani em Mato Grosso do Sul. In: PROUS, A; LIMA, T. A (eds.). Os Ceramistas Tupiguarani. Belo Horizonte: Sigma, 2008. p. 149-178.

MARQUES, L. R. R. A Produção do Artesanato Guarani no Município de Dourados, Mato Grosso do Sul. Dissertação (Mestrado em Meio Ambiente e Desenvolvimento Regional) - Universidade Anhanguera, 2016.

MÉTRAUX, A. A Civilização Material das Tribos Tupi-Guarani. Campo Grande: Gráfica Ed. Alvorada, 2012.

Armas. In: RIBEIRO, D. (ed.). Suma Etnológica Brasileira, v. 2. Petrópolis: Vozes, 1987. p. 139-161.

PASCHOALICK, L. C. A. A arte dos índios kaiowá da Reserva Indígena de Dourados-MS: transformações e permanências, uma expressão de identidade e afirmação étnica. Dourados: Ed. UFGD, 2008.

QUADROS, E. L. A defesa do modo de ser Guarani: o caso de Caró e Pirapó em 1628. Porto Alegre: Edigal, 2012.

RIBEIRO, B. G. O índio na história do Brasil. São Paulo: Global, 1984.

Dicionário do Artesanato Indígena. São Paulo: Editora da Universidade de São Paulo, 1988.

RIBEIRO, D. Suma Etnológica Brasileira. Atualizada do Handbook of South American Indians. Tecnologia Indígena. 2 ed. Petrópolis: Vozes, 1987.

Os índios e a civilização: a integração das populações indígenas no Brasil Moderno. São Paulo: Companhia das Letras, 1996.

SANTANA JUNIOR, J. R. Produção e reprodução indígena: o vir e o porvir na Reserva de Dourados/MS. Revista de Geografia Agrária, Uberlândia, v. 5, n. 9, p. 203-236, 2010.

SCHADEN, Egon. Aspectos fundamentais da cultura guarani. São Luiz: Difusão Europeia do Livro, 1963

SEEGER, A. Novos horizontes na classificação dos instrumentos musicais. In: 
RIBEIRO, B. (ed.). Suma Etnológica Brasileira, v. 3. Petrópolis: Vozes, 1987. p. 173179.

SILVA, C. E. Publicação eletrônica [mensagem pessoal]. Mensagem recebida por leilaroque@gmail.com em 3 mar. 2015.

SOARES, J. A. B.; PEREIRA.J. G. Diagnóstico Ambiental da Reserva Indígena de Dourados - MS. In: IBEAS - Instituto Brasileiro de Estudos Ambientais .VI Congresso Brasileiro de Gestão Ambiental Porto Alegre/RS - 23 a 26/11/2015, Porto Alegre, 2015. Disponível em: 〈http://www.ibeas.org.br/congresso/Trabalhos2015/XI-058.pdf>. Acesso em 27 mar. 2016.

WENCESLAU, M. E. O índio kayowá e a comunidade dos brancos. Dissertação (Mestrado em História Social) - Faculdade de Filosofia, Ciências, Letras e Ciências Humanas, Universidade de São Paulo. São Paulo: USP, 1990.

WILLEY, G. R. Cerâmica. In: RIBEIRO, D. (ed.). Suma Etnológica Brasileira, v. 2. Petrópolis: Vozes, 1987. p. 231-281. 